\title{
OPTIMIZATION OF THE STRENGTH PROPERTIES OF EXPANSIVE SOIL STABILIZED WITH AGRICULTURAL WASTES
}

\author{
* Mary Ann Q. Adajar ${ }^{1}$ and Kigia R. Valbuena ${ }^{1}$ \\ ${ }^{1}$ Department of Civil Engineering, De La Salle University, Philippines \\ *Corresponding Author, Received: 11 Nov. 2021, Revised: 01 Dec. 2021, Accepted: 18 Dec. 2021
}

\begin{abstract}
Expansive soils are problematic soils that exhibit shrink-swell behavior. Previous research has shown that $20 \%$ rice husk ash (RHA) effectively reduces the swelling potential of expansive soils, but it does not increase the strength of the soil. An improved admixture composed of RHA and a binder was used to treat the expansive soil. Different types of binders were used; three of which are agricultural wastes namely coconut shell ash (CSA), rice straw ash (RSA), and sugarcane bagasse ash (SCBA). Ordinary Portland cement (OPC) was used as a comparison for the other binders. The untreated and treated soil mixtures were evaluated through the unconfined compressive strength (UCS) and expansion index (EI). The effectivity of the admixture is evaluated through ASTM D4609. The treated specimens exhibited an increased in the strength as the curing days increases. A response surface methodology was performed for the UCS of the soil mixtures with the binder types of CSA, RSA, and SCBA. The binder content and curing period are the numerical factors and the response is the UCS. Contour plots and response surface plots showed that the optimum strength for the mixtures with CSA, RSA, and SCBA is at the highest curing period of 35 days and lowest binder content (5\% content). The binder type that has the highest maximum value for the predicted response is the RSA, therefore, the optimum mixture is the soil with 5\% RSA combined with 20\% RHA.
\end{abstract}

Keywords: Expansive soils, Agricultural wastes, Unconfined compressive strength, Expansion index, Response surface methodology

\section{INTRODUCTION}

Expansive soils are clay soils that shrink and swell, exhibiting an extreme change in volume. The damaging effects of expansive soils are exacerbated in fluctuating climates such as the Philippines. Temperature changes trigger the shrink-swell phenomena in the soil that will lead to the failure of the soil and ultimately the structure above it. Expansive soils are prevalent in the Philippines due to the extensive deposition of volcanic ash [1]. The Philippines is also abundant in fertile soils, among which include smectite type of clays, which are very prone to shrinking and swelling upon drying and wetting [2]. Expansive soils can cause extensive damage to structures if undetected and overlooked before construction. It is stipulated in the National Structural Code of the Philippines (NSCP) that where expansive soils are present under foundations, they should be removed or stabilized around and beneath the structure [3].

There are already numerous existing mechanical or chemical solutions for expansive soils. However, these are not always practical or economical. Removal and replacement of expansive soils can also be done but it is not always preferred due to its high cost. A sustainable and more cost-effective alternative would be to make use of admixtures composed of agricultural waste that have cementitious properties. It has been found that waste materials can replace cement even up to $70 \%$ while providing environmentally safe, sound, and low-cost structures [4]. RHA has already been found to be successful in mitigating the swelling potential of expansive soils; however, it does not increase the strength of the soil alone [5]. A binding agent should be used together with RHA to improve its quality and efficiency as a soil stabilizer.

Agricultural wastes contain pozzolanic property, making them good supplementary cementitious materials [6]. In the Philippines, large quantities of agricultural wastes are produced yearly, creating a pollution problem. Rice husk, sugarcane bagasse, and coconut shells produced more than three million metric tons, over five million metric tons, and more than two million metric tons of waste biomass from 2010-2011, respectively. Rice straw produced a staggering amount of over sixteen million metric tons during the same period [7].

There is great potential for using agricultural wastes as binders particularly CSA, RSA, and SCBA due to their pozzolanic characteristic [8][10]. Coconut shells subjected to uncontrolled combustion to produce CSA were found to be a suitable partial replacement for cement in the production of concrete [8]. RSA satisfies the minimum requirements of a pozzolana according to the ASTM standards, making it a good replacement for cement [9]. SCBA has a high percentage of silica which allows it to have a binding property. In 
a study, an increase in the strength of expansive soil was observed when SCBA and lime were used. Further, the addition of SCBA to lime is more effective than lime alone in decreasing the swelling potential of the soil [10].

The main objective of this study is to determine the optimum amount of admixture in treating expansive soils under dry curing conditions that will reduce the swelling potential and produce the maximum strength of the soil. The RHA-soil mixture for controlling soil expansion will be enhanced by adding different proportions of CSA, SCBA, and RSA. The effectivity of the admixture is evaluated using the expansion index (EI), Atterberg limits, maximum dry density, optimum moisture content (OMC), and unconfined compressive strength (UCS). The response surface methodology (RSM) was used to optimize the response of interest, the UCS, which is influenced by the type of binder, binder content, and the curing period.

\section{RESEARCH SIGNIFICANCE}

This study helps alleviate the environmental burden brought about by the agricultural wastes by incorporating CSA, RSA, and SCBA together with RHA as stabilizing agents for expansive soils. Using agricultural wastes and industrial wastes for engineering purposes is a sustainable method of disposing these large quantities of waste materials. With the raw materials of the enhanced RHA-soil mixture readily available and inexpensive unlike cement and lime, the use of CSA, RSA, and SCBA as alternative cementitious materials will be beneficial for the environment while also lessening the cost of stabilizing soils.

\section{MATERIALS AND METHODS}

\subsection{Material Sourcing}

The expansive soil was obtained from Kauswagan, Lanao del Norte. It was already used in a previous study that confirmed its shrink-swell tendencies [11]. RHA was obtained from a biomass powerplant in Muntinlupa City that uses rice husk as fuel. The CSA, RSA and SCBA were source out from various local farmers in the Philippines.

\subsection{Experimental Procedure}

The index properties of the untreated soil were obtained for soil classification. The index properties were evaluated using the NSCP specifications for expansive soil as shown in Table 1 to determine the potential expansion of the soil.
Table 1 Specifications for Expansive Soil [3]

\begin{tabular}{cc}
\hline Property & Required Value \\
\hline Percent Passing No. 200 & $>10 \%$ \\
Sieve (\%) & $>10 \%$ \\
Percent Passing 5 $\mu \mathrm{m}(\%)$ & $>50 \%$ \\
Liquid Limit, LL (\%) & $>15 \%$ \\
Plasticity Index, PI (\%) & $>20$ \\
Expansion Index, EI & \\
\hline
\end{tabular}

Standard procedures from ASTM were followed for all the laboratory tests as shown in Table 2 . These tests were performed on both untreated and treated samples. The preliminary data includes the specific gravity, grain size analysis, Atterberg limits, and the moisture-density relationship. The effectiveness of the admixture is evaluated through ASTM D4609. The indicators for improvement are shown in Table 3.

Table 2 Laboratory Tests

\begin{tabular}{cc}
\hline Experimental Program & Test Standard \\
\hline Specific Gravity & ASTM D854 \\
Grain Size Analysis & ASTM D422 \\
Atterberg Limits & ASTM D4318 \\
Moisture-Density & ASTM D698 \\
Relationship & ASTM D4829 \\
Expansion Index & ASTM D2166 \\
Unconfined Compressive & \\
Strength &
\end{tabular}

Table 3 Criteria to Gauge the Effectiveness of Admixture (ASTM D4609)

\begin{tabular}{cc}
\hline Property & Indicator for Improvement \\
\hline Liquid Limit & Significant reduction \\
Plasticity Index & Significant reduction \\
Maximum Dry & Increase by more than 80 \\
Density & $\mathrm{kg} / \mathrm{m}^{3}$ \\
Optimum & Decrease by more than \\
Moisture Content & $15 \%$ \\
Unconfined & Increase by $345 \mathrm{kPa}$ or \\
Compressive & more \\
Strength & \\
\hline
\end{tabular}

\subsection{Soil Mixture Preparation}

Dry mix proportioning made use of the preliminary data. The soil mixtures were created by replacing a percentage of the untreated soil's volume with RHA and binder. The RHA content is held constant at $20 \%$ while the binder content 
ranges from $5 \%$ to $20 \%$ in increment of $5 \%$. Twenty percent RHA is used in this study as the stabilizer because it is the recommended value to effectively reduce the swelling potential of expansive soil [5].

The dry mixture was mixed with water at optimum moisture content to make the total soil mixture for the EI test and the UCS test. For the UCS test, there were five specimens prepared for each variation of the soil mixture.

The samples were placed in the airtight containers to cure for at least 16 hours. The cured samples were compacted into molds then extruded. Immediately after casting, the specimens were sealed with plastic wrap for at least seven days. The specimens were unsealed after seven days and subjected to the drying curing condition. The specimens were cured up to 14, 21, 28 and 35 days from casting.

\section{TEST RESULTS}

\subsection{Soil Classification}

The index properties of the soil used in this study met most of the criteria set by the NSCP for expansive soils as shown in Table 4. The soil is classified as expansive because of its expansion index that is the governing property to classify expansive soils. Its expansion index value of 98 indicates that it has high expansion potential. Based on the Unified Soil Classification System (USCS), the soil sample is elastic silt (MH).

Table 4 Summary of Soil Classification

\begin{tabular}{cccc}
\hline Property & $\begin{array}{c}\text { Required } \\
\text { Value }\end{array}$ & Result & Remarks \\
\hline $\begin{array}{c}\text { Percent } \\
\text { Passing No. }\end{array}$ & $>10 \%$ & 54.82 & Pass \\
$\begin{array}{c}\text { 200 Sieve (\%) } \\
\text { Percent }\end{array}$ & & & \\
$\begin{array}{c}\text { Passing 5 } \mu \mathrm{m} \\
(\%)\end{array}$ & $>10 \%$ & N/A & Fail \\
$\begin{array}{c}\text { Liquid Limit, } \\
\text { LL (\%) }\end{array}$ & $>50 \%$ & 76.93 & Pass \\
$\begin{array}{c}\text { Plasticity } \\
\text { Index, PI (\%) } \\
\text { Expansion } \\
\text { Index, EI }\end{array}$ & $>15 \%$ & 32.85 & Pass \\
\hline
\end{tabular}

\subsection{Evaluation of Effectiveness of Admixture}

\subsubsection{Atterberg Limits}

The behavior of the soil under varying moisture contents can be determined using the Atterberg limits. According to ASTM D4609, an admixture is effective when there is a significant reduction in the liquid limit and the plasticity index. The summary of the test results for the Atterberg limits is shown in Table 5.

Table 5 Summary of Results for Atterberg Limits

\begin{tabular}{cccc}
\hline $\begin{array}{c}\text { Binder } \\
\text { Content }\end{array}$ & $\begin{array}{c}\text { Liquid } \\
\text { Limit, } \\
\text { LL }(\%)\end{array}$ & $\begin{array}{c}\text { Plastic } \\
\text { Limit, } \\
\text { PL }(\%)\end{array}$ & $\begin{array}{c}\text { Plasticity } \\
\text { Index, } \\
\text { PI }(\%)\end{array}$ \\
\hline $0 \%$ & 77 & 44 & 33 \\
$5 \%$ CSA & 93 & 49 & 44 \\
$10 \%$ CSA & 83 & 46 & 37 \\
$15 \%$ CSA & 83 & 47 & 36 \\
$20 \%$ CSA & 82 & 45 & 37 \\
$5 \%$ RSA & 75 & 46 & 29 \\
$10 \%$ RSA & 75 & 45 & 29 \\
$15 \%$ RSA & 74 & 45 & 30 \\
$20 \%$ RSA & 72 & 42 & 30 \\
$5 \%$ SCBA & 81 & 45 & 36 \\
$10 \%$ SCBA & 80 & 46 & 34 \\
$15 \%$ SCBA & 79 & 43 & 36 \\
$20 \%$ SCBA & 77 & 47 & 30 \\
$5 \%$ OPC & 74 & 46 & 27 \\
$10 \%$ OPC & 72 & 47 & 25 \\
$15 \%$ OPC & 67 & 43 & 24 \\
$20 \%$ OPC & 65 & 41 & 24 \\
\hline
\end{tabular}

The liquid limit and the plasticity index values of the mixtures are generally decreasing. The reduction in the liquid limit and plasticity index is due to the replacement of clay particles with nonplastic materials.

The liquid limit exhibited a maximum decreased of $6.5 \%$ and $15.6 \%$ for the mixtures with RSA and cement, respectively, in comparison to untreated soil. Conversely, it could be observed that the mixtures containing CSA and SCBA have liquid limit values significantly higher compared to the untreated soil. The microstructure of the CSA and SCBA allowed more water to be absorbed.

The plasticity index was reduced by as much as $12 \%$ when RSA acted as the binder. Cement mixtures also show a reduction by as much as $27 \%$ in the plasticity index. A study that used cement and RHA as additives also saw a reduction in the plasticity of the soil [12]. On the other hand, most mixtures with CSA and SCBA have values for plasticity index higher than the untreated soil. In a study that used coconut shell powder, the plasticity index also increased as the additive increased [13]. In another study that used SCBA, the liquid limit and plasticity index decreased as the additive increased [14]. This difference in the trend observed could be because the SCBA used in this study was 
not burned in a controlled condition. Overall, the RSA and cement improved the soil while the CSA and SCBA did not.

\subsubsection{Moisture-Density Relationship}

Most soils show a relationship between their moisture content and dry density when placed under a compactive effort. The optimum moisture content (OMC) and maximum dry unit weight are performance indicators of the admixture as per ASTM D4609. Table 6 shows the summary of the results obtained through the Standard Proctor Test.

The reduction in the maximum dry unit weight observed for all mixtures could be attributed to the lower specific gravity of the stabilizer and binder compared to the soil. The RHA used in this study has a specific gravity of 1.555 [5]. The CSA, RSA, and SCBA have specific gravity values of 1.154 , 1.844 , and 1.544 , respectively, while the soil has a specific gravity of 2.713 .

The OMC of the soil increased by $2.24 \%$ to $34.23 \%$ when incorporated with the stabilizer and different types of a binder. The increase in the OMC is attributed to the porosity of the RHA [12]. The presence of $20 \%$ RHA in all the mixtures greatly affected the results of the moisture-density relationship test.

Table 6 Summary of Results for Moisture-Density Relationship

\begin{tabular}{ccc}
\hline Binder & $\begin{array}{c}\text { Maximum } \\
\text { Dry Unit } \\
\text { Weight } \\
\left(\mathrm{kN} / \mathrm{m}^{3}\right)\end{array}$ & $\begin{array}{c}\text { Optimum } \\
\text { Moisture } \\
\text { Content } \\
(\%)\end{array}$ \\
\hline $0 \%$ & 14.03 & 35.73 \\
$5 \%$ CSA & 9.55 & 44.9 \\
$10 \%$ CSA & 10.06 & 46.93 \\
$15 \%$ CSA & 9.61 & 46.53 \\
$20 \%$ CSA & 9.36 & 47.35 \\
$5 \%$ RSA & 11.03 & 40.08 \\
$10 \%$ RSA & 11.20 & 40.23 \\
$15 \%$ RSA & 11.38 & 39.2 \\
$20 \%$ RSA & 11.67 & 38.85 \\
$5 \%$ SCBA & 9.53 & 47.96 \\
$10 \%$ SCBA & 9.84 & 46.94 \\
$15 \%$ SCBA & 9.66 & 48.57 \\
$20 \%$ SCBA & 9.50 & 47.76 \\
$5 \%$ OPC & 11.83 & 30.58 \\
$10 \%$ OPC & 12.23 & 36.53 \\
$15 \%$ OPC & 12.76 & 37.31 \\
$20 \%$ OPC & 12.38 & 37.88 \\
\hline
\end{tabular}

Of the three (3) types of agricultural wastes as binder, it is the RSA that gives the highest maximum dry unit weight with the lower value of OMC. The compaction curve of the soil-RSA mixture is shown in Fig. 1. Overall, none of the binders showed an improvement in the compaction characteristics of the soil.

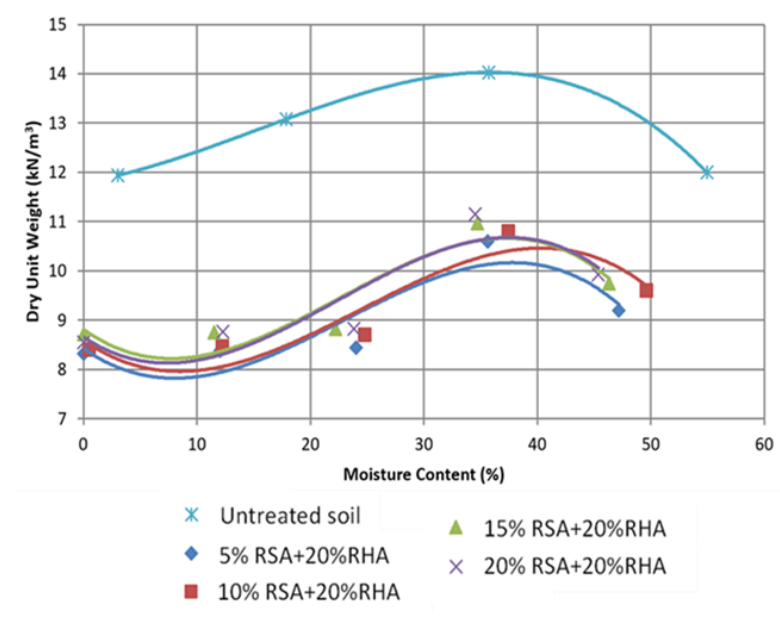

Fig. 1 Compaction curve of soil-RSA mixture

\subsubsection{Unconfined Compressive Strength}

Most of the soil mixtures met the required provisions set by ASTM D4609 for the indication of improvement in strength. The mixtures containing agricultural wastes as binders have values for unconfined compressive strength (UCS) that are generally increasing as the curing period increases. The consistency of the specimens changed from very stiff to hard under the drying curing condition and with an increased curing period. A similar study also found that the specimens under drying conditions yielded a higher compressive strength than that of the sealed condition due to carbonation and suction [15].

The mixtures with cement did not show a trend for the curing period and binder content because the dry curing condition inhibited the hydration process. The increase in strength after the 35-day curing period is represented in Fig. 2.

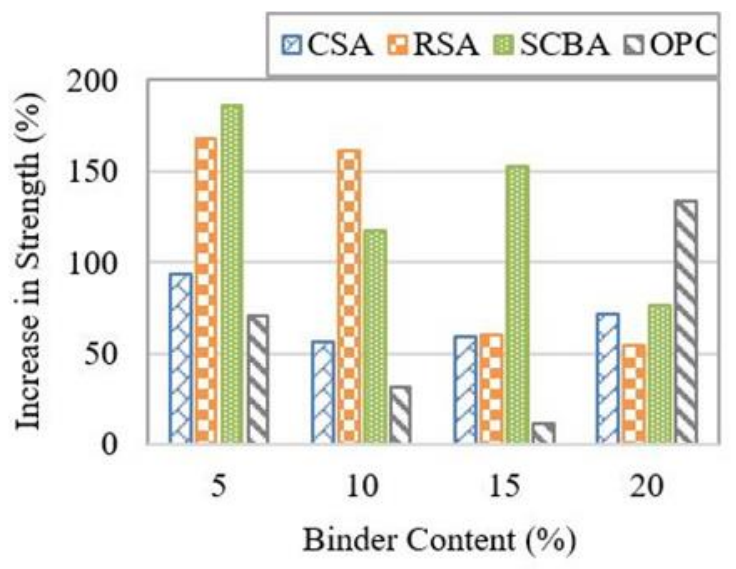

Fig. 2 Increase in UCS at 35 days curing period 
A high strength was achieved by the soil mixtures with RSA and SCBA with 5\% binder content while the soil mixtures with cement require the maximum binder content to achieve a strength that may not always be as high. OPC is not an ideal binder for expansive soils not only for being uneconomical but also because of its poor and inconsistent performance when subjected to the dry curing condition.

\subsection{Expansion Index}

With the addition of the stabilizer and binder, the potential expansion of the mixtures became very low. The EI of the mixtures ranged from 0 to 2 only. This reaffirms the effectiveness of $20 \%$ RHA as a stabilizer. It also indicates that the binder had little to no effect on the expansion of the soil, even though the microstructures of CSA, RSA, and SCBA allow more water to be absorbed by the mixture.

\subsection{Optimization of the Strength Using Response Surface Methodology}

The optimum mixture is chosen based on the response surface method. The response surface methodology was performed using the DesignExpert software. The curing period and binder content are the numerical factors. The minimum value of the curing period is 14 days while the maximum is 35 days. The minimum value for the binder content is $5 \%$ while the maximum is $20 \%$. Cement is not considered in the optimization because it only served as a comparison for the other binders in terms of effectiveness. A response surface quadratic model was produced for each binder type. Statistical analysis revealed that the models are significant and adequate to represent the relationship between the response and the independent variables. There is only one response which is the unconfined compressive strength.

Three-dimensional (3D) surface plots are produced by the models shown in Figs. 3 to 5. The highest strength is always achieved in the upper left portion of the surfaces, which means that the optimum strength is at the highest curing period (35 days) and lowest binder content (5\% content) for the binder types CSA, RSA, and SCBA. The strength of the CSA, RSA, and SCBA mixtures increases over time due to the drying curing condition that gives the specimens a hard consistency. Additionally, the cohesion of the particles is improved over time. The ashes are non-cohesive, and they have a microstructure full of voids; therefore, the lowest binder content is desirable.

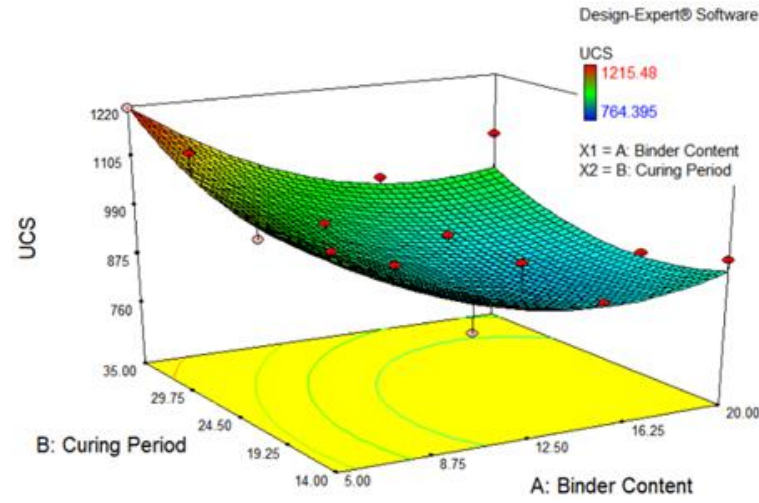

Fig. 3 Response surface plot of curing period and binder content (CSA as binder type)

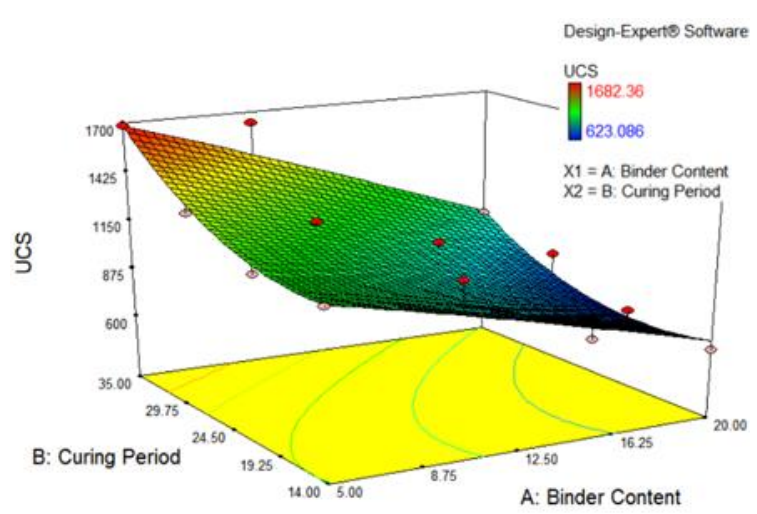

Fig. 4 Response surface plot of curing period and binder content (RSA as binder type)

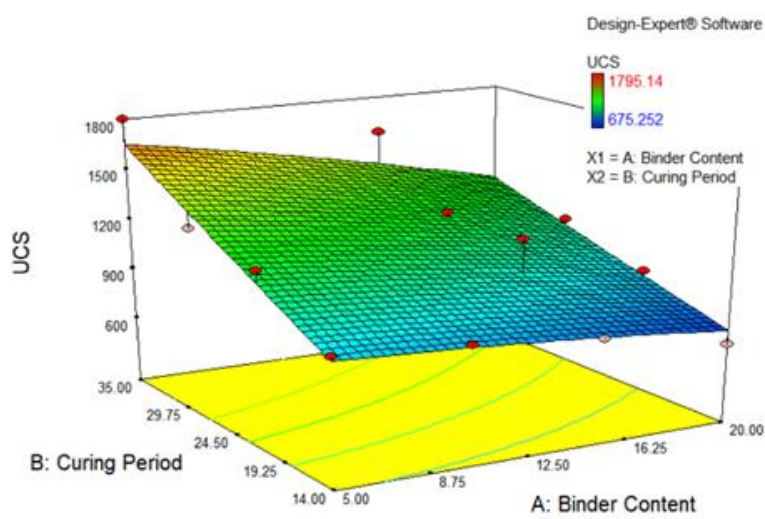

Fig. 5 Response surface plot of curing period and binder content (SCBA as binder type)

The equations of the UCS generated from the ANOVA were used to obtain the predicted maximum value of the strength for each binder type. The equations produced by the models are as follows: 


$$
\begin{aligned}
& U C S_{C S A}=1432.809-49.460(B C) \\
& -18.361(C P)-0.27(B C)(C P) \\
& +1.746\left(B C^{2}\right)+0.555\left(C P^{2}\right) \\
& U C S_{R S A}=1582.026-16.791(B C) \\
& -39.551(C P)-0.695(B C)(C P) \\
& -0.242\left(B C^{2}\right)+1.385\left(C P^{2}\right) \\
& U C S_{S C B A}=426.154+9.277(B C) \\
& +35.513(C P)-0.840(B C)(C P) \\
& -0.329\left(B C^{2}\right)+0.075\left(C P^{2}\right)
\end{aligned}
$$

Where:

$\mathrm{UCS}_{\mathrm{CSA}}=\mathrm{UCS}$ of Mixtures with CSA $(\mathrm{kPa})$

$\mathrm{UCS}_{\mathrm{RSA}}=\mathrm{UCS}$ of Mixtures with RSA $(\mathrm{kPa})$

$\mathrm{UCS}_{\mathrm{SCBA}}=\mathrm{UCS}$ of Mixtures with $\mathrm{SCBA}(\mathrm{kPa})$

$\mathrm{BC}=$ Binder Content $(\%)$

$\mathrm{CP}=$ Curing Period (days)

The UCS can be obtained using the final equation in terms of the actual factors. The equations for the predicted response in terms of the actual factors were used to compare the maximum UCS values as shown in Table 7. The values used for the factors are those that would produce the maximum, which is $5 \%$ for the binder content, and 35 days for the curing period. The binder type that has the highest maximum value for the predicted response is the RSA, therefore, the optimum mixture is the soil with 5\% RSA.

Table 7 Maximum Values for the Predicted UCS for Each Binder Type

\begin{tabular}{cccc}
\hline Binder Type & $\begin{array}{c}\text { Binder } \\
\text { Content } \\
(\%)\end{array}$ & $\begin{array}{c}\text { Curing } \\
\text { Period } \\
(\text { days })\end{array}$ & $\begin{array}{c}\text { Predicted } \\
\text { UCS } \\
(\mathrm{kPa})\end{array}$ \\
\hline CSA & 5 & 35 & 1219.120 \\
RSA & 5 & 35 & 1682.124 \\
SCBA & 5 & 35 & 1651.952 \\
\hline
\end{tabular}

\section{CONCLUSION}

The soil used in this study was sourced from Kauswagan, Lanao del Norte. It is identified as an expansive soil due to its index properties meeting the criteria set by the NSCP for expansive soils. $20 \%$ RHA was used as the stabilizer for the soil since it has been proven to effectively reduce the swelling potential of the soil. CSA, RSA, SCBA, and OPC were added in varying percentages from $5 \%$ to $20 \%$ in steps of $5 \%$ as the binder.

With the addition of the stabilizer and binder, the potential expansion of the mixtures was reduced to very low. The treated soil with rice straw ash
(RSA) as binder showed a significant reduction in Atterberg limits which is one of the indication that the admixture is effective. None of the mixtures showed improvement in the compaction characteristics. Improvement in unconfined compressive strength was observed for all binder types and satifies the requirement for the admixtures to be effective. OPC is not an ideal binder for expansive soils because of its poor performance in drying conditions.

A response surface methodology was performed for the unconfined compressive strength of the soil mixtures. The optimum strength for each binder is at the lowest binder content, and the strength increases with the curing period. The optimum mixture is the soil with 5\% rice straw ash (RSA) as binder combined with $20 \%$ rice husk ash (RHA). The mixture yielded the highest maximum value for the predicted UCS.

It is recommended to investigate the long-term strength of the treated expansive soils and with curing methods that will simulate the actual condition on site.

\section{REFERENCES}

[1] Morales E. and Morales M. K., Expansive Soils - Identification, Detection and Remediation Strategies, $\quad$ Retrieved from http://www.pgatech.com.ph, 2007.

[2] Carating, R. B., Galanta, R. G., and Bacatio, C. D., The Soils of the Philippines, Springer Science \& Business, 2014.

[3] Association of Structural Engineers of the Philippines (ASEP), National Structural Code of the Philippines, 2010.

[4] Khan, R., Jabbar, A., Ahmad, I., Khan, W., Khan, A., and Mirza, J., Reduction in Environmental Problems using Rice-husk Ash in Concrete. Construction and Building Materials, Vol. 30, 2011, pp. 360-365.

[5] Adajar, M. Q., Aquino, C. P., Dela Cruz II, J. D., Martin, C. H., and Urieta, D. G., Investigating the Effectiveness of Rice Husk Ash as Stabilizing Agent of Expansive Soil. International Journal of GEOMATE, Vol. 16, Issue 58, 2019, pp. 33-40.

[6] Alex, J., Dhanalakshmi, J., and Ambedkar, B., Experimental investigation on rice husk ash as cement replacement on concrete production. Construction and Building Materials, Vol. 127, 2016, pp. 353-362.

[7] Baconguis, S. R., and Pasagdan, A. R., Waste biomass statistics in the Philippines. Canopy International, 2013, pp. 8-9.

[8] Adajar, M., Galupino, J., Frianeza, C., Aguilon, J., Sy, J., and Tan, P., Compressive Strength and Durability of Concrete with Coconut Shell 
Ash as Cement Replacement. International Journal of GEOMATE, Vol. 18, Issue 70, 2020, pp. 183-190.

[9] El-Sayed, M. A., and El-Samni, T. M., Physical and Chemical Properties of Rice Straw Ash and Its Effect on the Cement Paste Produced from Different Cement Types. Journal of King Saud University - Engineering Sciences, Vol. 19, Issue 1, 2006, pp. 21-29.

[10]Hasan, H., Dang, L., Khabbaz, H., Fatahi, B., and Terzaghi, S., Remediation of Expansive Soils Using Agricultural Waste Bagasse Ash. Procedia Engineering, Vol. 143, 2016, pp. 1368-1375.

[11]Tan, J. F., and Adajar, M. Q., Recycled Gypsum and Rice Husk Ash as Additives in the Stabilization of Expansive Soil. International Journal of GEOMATE, Vol. 18, Issue 70, 2020, pp. 197-202.

[12] Basha, E. A., Hashim, R., Mahmud, H. B., and Muntohar, A. S., Stabilization of Residual Soil with Rice Husk Ash and Cement. Construction and Building Materials, Vol. 19, Issue 6, 2005, pp. $448-453$.

[13] Oluwafemi, I. J., Laseinde, T. O., and Akinwamide, J., Data Showing the Effects of Geotechnical Properties of Lateritic Soil Mixed with Coconut Shell Powder in Ado-Ekiti, South Western Nigeria. Data in Brief, Vol. 24, 2019.

[14] Barasa, P. K., Too, D., Jonah K., and Mulei, S., Stabilization of Expansive Clay Using Lime and Sugarcane Bagasse Ash. International Journal of Science and Research, 2015, pp. 2112-2117.

[15]Ho, L. S., Nakarai, K., Ogawa, Y., Sasaki, T., and Morioka, M., Strength Development of Cement-treated Soils: Effect of Water Content, Carbonation, and Pozzolanic Reaction under Drying Curing Condition. Construction and Building Materials, pp. 703-712.

Copyright (C) Int. J. of GEOMATE All rights reserved, including making copies unless permission is obtained from the copyright proprietors. 